Gut, 1984, 25, 129-132

\title{
Injection sclerotherapy for oesophageal varices: a prospective randomised trial of different treatment schedules
}

\author{
D WESTABY, W M MELIA, B R D MACDOUGALL, \\ J E HEGARTY, AND ROGER WILLIAMS
}

From the Liver Unit, King's College Hospital and Medical School, Denmark Hill, London

SUMmARY A prospective randomised study to compare the efficacy and complications of injection sclerotherapy carried out at intervals of one week and three weeks up to the time obliteration of varices was achieved, was undertaken in 55 patients (48 cirrhosis, six portal vein thrombosis, one nodular regenerative hyperplasia). The number of courses of injection required for obliteration of the varices was not different in the two groups and despite a shorter time scale for obliteration in the weekly treated patients the frequency with which further episodes of bleeding occurred before that was not significantly less. Mucosal ulceration during the period required for obliteration was observed at endoscopy more frequently in the weekly treated patients but was not associated with a greater frequency of postinjection pain, dysphagia or of long term stricture formation.

In a controlled clinical trial of injection sclerotherapy reported by us ${ }^{1}$ an interval of three weeks was allowed between each course of injection. Others have used shorter intervals, ${ }^{2}$ the advantages of which could be more rapid obliteration of the varices and an earlier return to work and normal activity for the patient. Furthermore, if variceal obliteration could be achieved within a shorter period this might also lead to a reduction in the frequency of recurrent variceal bleeding during this time; which occurred in $40 \%$ of our patients. ${ }^{1}$ On the other hand, our early experience with injection sclerotherapy when the rigid oesophagoscope was used suggested that injection at intervals of less than three weeks was associated with a high frequency of oesophageal mucosal ulceration. The present controlled study was designed to compare the efficacy and complications associated with injection sclerotherapy when carried out at one week as compared with three week intervals.

\section{Methods}

PATIENTS

The investigation was undertaken in a group of 55 patients, 48 with a biopsy proven cirrhosis, six with

Address for correspondence: Dr R Williams, Liver Unit, King's College Hospital \& Medical School, Denmark Hill, London SE5 8RX.

Received for publication 24 April 1983 portal vein thrombosis (confirmed by ultrasound and aortoportography) and one patient with nodular regenerative hyperplasia of the liver. In each of the patients variceal bleeding was confirmed by endoscopy, and variceal size at the gastrooesophageal junction was graded $1+, 2+$, or $3+$ according to the following criteria: grade $1+:$ varix is flush with the wall of the oesophagus; grade $2+$ : protrusion of the varix no further than half way to the centre of the oesophageal lumen; and grade 3+: protrusion more than half way to the centre of the lumen. ${ }^{3}$ The severity of the underlying liver disease, at the time of presentation was assessed by using a modification of Child's classification. ${ }^{4}$ After control of the initial bleed by blood transfusion and intravenous vasopressin, together with balloon tamponade when required, the patients were allocated to the two treatment groups by a system of random numbers ( 28 to one weekly intervals; 27 to three weekly intervals). The first course of injections was given after the patient had been haemodynamically stable for about three to six hours or in those who had required balloon tamponade, at the time the Sengstaken-Blakemore tube was removed. In both treatment groups the technique of fibreoptic endoscopy (GIF-K series; Olympus) together with a flexible sheath (Williams Tube; Keymed), as previously described ${ }^{5}$ was used. Injections were placed intravascularly with a maximum of $5 \mathrm{ml} 5 \%$ 
ethanolamine oleate per varix and the aim was to obliterate only those varices at the gastrooesophageal junction (squamous-mucous junction). As is now our policy for injection sclerotherapy using the sheath technique, the procedure was carried out under intravenous diazepam sedation with the addition of pentazocine as required. ${ }^{6}$ Patients remained in hospital for 24-48 hours after the procedure except in those instances when recurrent bleeding or other complications of liver disease required prolonged treatment.

If at the time of subsequent courses of injection acute mucosal ulceration with slough in the base was found to overlay two or more varices, further injection was delayed in order to avoid full thickness oesophageal wall necrosis which has been described by others. ${ }^{2}$ In such cases a period of three weeks was allowed before healing was assessed by endoscopy.

The efficacy of the two intervals of injection was assessed by the number of courses required to achieve obliteration of the varices and also from the period of time needed for this. Further episodes of bleeding (requiring one or more units of blood transfusion) during this period were recorded and compared. With respect to complications we looked in particular at the frequency of mucosal ulceration in the lower oesophagus and stricture formation during the subsequent follow up period.

Comparison of the two groups with respect to bleeding, complications, and the number of courses of injection required to obliterate the varices was made by $\chi^{2}$ test. Analysis of the period of time to achieve obliteration for the two groups was made by a Desu comparison (analogous to that used for life table anaylsis). The study was approved by the Ethical Committee of King's College Hospital and Medical School and informed consent was obtained from all patients.

\section{Results}

Comparison of clinical data at entry into the trial (Table) showed a greater number of patients with grade $\mathrm{C}$ liver disease in the three week interval group and a larger number with $3+$ as compared with $2+$ variceal size in those injected weekly, although in neither case was the difference statistically significant.

The number of courses of injection required to achieve variceal obliteration was similar for the two groups (mean 4.2 and $4 \cdot 1$, one weekly and three weekly respectively, Fig. 1) although the period of time over which this occurred was significantly shorter in the patients injected at weekly intervals with a mean of five weeks as compared with nine weeks for those treated at three weekly intervals
Table Comparison of clinical data for the two interval groups at the time of entry into the study

\begin{tabular}{lll}
\hline & $\begin{array}{l}1 \text { week } \\
(n=28)\end{array}$ & $\begin{array}{l}3 \text { week } \\
(n=27)\end{array}$ \\
\hline Mean age (years) & $50 \cdot 1 \pm 14 \cdot 8$ & $55 \cdot 0 \pm 12 \cdot 5$ \\
Sex ratio F:M & $13: 15$ & $7: 20$ \\
Cirrhosis & 23 & 25 \\
$\quad$ Alcohol & 9 & 15 \\
Cryptogenic & 4 & 3 \\
Chronic active hepatitis & 6 & 3 \\
Primary biliary cirrhosis & 2 & 3 \\
Budd-Chiari syndrome (chronic) & 2 & 1 \\
Modified Child's Grade & & \\
(patients with cirrhosis) & 4 & 5 \\
A & 11 & 8 \\
B & 8 & 12 \\
C & 4 & 2 \\
Portal vein thrombosis & 1 & - \\
Nodular regenerative hyperplasia & & \\
Variceal size & 6 & 11 \\
2+ & 22 & 16 \\
3+ & & \\
\hline
\end{tabular}

(p<0.05, Fig. 2). Further episodes of variceal bleeding in the period before obliteration was achieved occurred less frequently in those treated at one week intervals (11 of 28 patients with a total of 12 bleeds) compared with those injected in the three week interval group (14 of 27 with a total of 19 bleeds) but the difference was not statistically significant $(\mathrm{p}>0 \cdot 30)$. Approximately $70 \%$ of all episodes occurred during the first three weeks after the first course of injection irrespective of the interval at which the injections were carried out. When the overall frequency of rebleeding in the period up to obliteration is considered in relation to the Child's category there were no significant differences found. Thus $10(50 \%)$ of the 20 patients with grade $\mathrm{C}$ liver disease bled as compared with

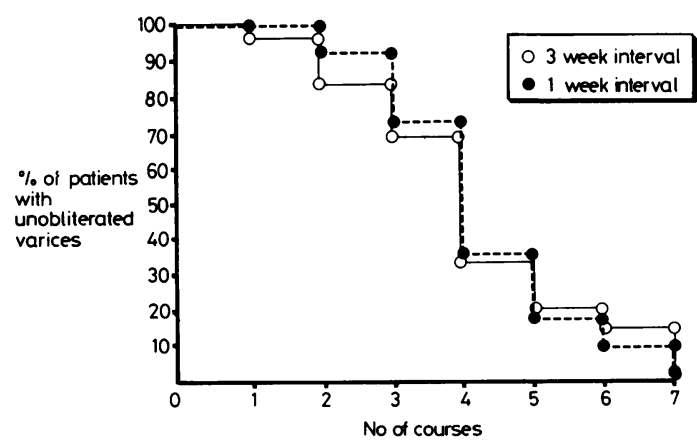

Fig. 1 Percentage of patients in each group with residual varices in relation to number of courses of injection sclerotherapy. 


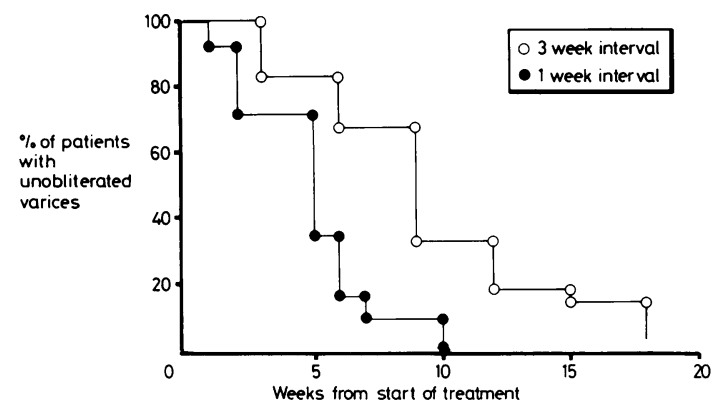

Fig. 2 Percentage of patients in the one week and three week interval groups with residual varices at intervals after the start of injection sclerotherapy. Time period to obliteration in one week interval group includes delay in further courses of injection when extensive ulceration was found at endoscopy.

eight (42\%) of 19 grade B and seven (44\%) of 16 grade $\mathrm{A}$ (including those with normal liver function in the absence of cirrhosis). Further episodes of variceal bleeding were more common in patients with $3+$ varices (19 of 38 ) compared with those with $2+$ varices (five of 17) but the difference was again not statistically significant $(p>0 \cdot 30)$.

Mucosal ulceration in the period up to obliteration was found in $80 \%$ of the patients treated once weekly and $30 \%$ of those at three week intervals $(p<0.01)$. The presence of ulceration overlying two or more of the varices on 19 occasions (four after two courses, 15 after three) all in the one week treatment group, led to a delay in further treatment. Of the 15 patients in the weekly treated group who required four or more courses of injection to obliterate the varices, all required a delay in treatment either after the second or third course on account of ulceration. In these instances a period of three weeks was usually sufficient for healing to occur and the next course of injection was carried out without incident at that time. In the three weekly injected group mucosal ulceration, when present, seldom involved more than one varix and was not responsible for a delay in further treatment. In six patients, two in the weekly and four in the three weekly treated group, ulceration overlying a varix was shown at endoscopy to be the site of a further episode of bleeding. The frequency of postinjection retrosternal chest pain and transient dysphagia (approximately $30 \%$ ) was similar in both treatment groups and there were no instances of oesophageal perforation or of either short or long term stricture formation.

There were five deaths in each group during the period up to obliteration; two of the five in the weekly and four of five in the three week interval group were as a direct consequence of recurrent variceal bleeding. Four patients died from liver failure unrelated to variceal bleeding, and there were no deaths which could be directly attributed to the use of injection sclerotherapy.

\section{Discussion}

Although injection at weekly intervals produced a more rapid obliteration of varices the frequency of recurrent bleeding up to the time of obliteration was not significantly reduced. The majority of such bleeding episodes occurred in the first three weeks after the start of treatment, a period when more than $70 \%$ of patients in both groups had residual varices, and it is therefore not surprising that no clear advantage with respect to rebleeding was observed with more frequent injections. The very high frequency with which mucosal ulceration occurred in the patients injected at one week intervals was not associated with more problems from retrosternal chest pain, dysphagia, or later stricture formation. This difference between the two treatment groups with respect to ulceration may, in part, be misleading with detection of ulceration after the preceding injection at the time of weekly endoscopy whereas this would have healed if endoscopy is carried out only after a three week interval. Nevertheless, more serious complications could have ensued in the weekly interval group if the policy of deferring treatment had not been followed when mucosal ulceration was found overlying two or more of the varices.

Overall the more rapid obliteration of varices, although not reducing the frequency of recurrent bleeding in this period, was regarded as an advantage by the majority of patients in that it allowed an earlier return to work and normal activity. The injection of varices at weekly intervals can be regarded as a safe regime with the provision that treatment is delayed in the presence of extensive mucosal ulceration, and our present regime is to give a maximum of three courses at this interval and then to allow a period of three weeks before reassessing, by endoscopy, the need for further injection.

We would like to thank the nursing staff of Todd Ward and the Endoscopy Suite for their care of the patients in this study.

\section{References}

1 Macdougall BRD, Westaby D, Theodossi A, Dawson 
JL, Williams R. Increased long-term survival in variceal haemorrhage using injection sclerotherapy. Results of a controlled trial. Lancet 1982; 1: 124-7.

2 Paquet KJ, Oberhammer E. Sclerotherapy of bleeding oesophageal varices by means of endoscopy. Endoscopy 1978; 10: 7-12.

3 Westaby D, Macdougall BRD, Saunders JB, Williams R. A study of risk factors in patients with cirrhosis and variceal bleeding. In: Westaby D, Macdougall BRD, Williams R, eds. Variceal bleeding. London: Pitman
Medical, 1982.

4 Pugh RNH, Murray-Lyon IM, Dawson JL, Pietroni MC, Williams R. Transection of the oesophagus for bleeding oesophageal varices. Br J Surg 1973; 60: 646-9. 5 Williams KGD, Dawson JL. Fibreoptic injection of oesophageal varices. $\mathrm{Br}$ Med J 1979; 2: 766-7.

6 Westaby D, Macdougall BRD, Melia WM, Theodossi A, Williams R. A prospective randomised study of two sclerotherapy techniques for oesophageal varices. Hepatology 1983 (in press). 